\title{
Easter Island's Collapse: A Tale of a Population Race
}

\author{
David de la Croix ${ }^{\mathrm{a}} \quad$ Davide Dottori $^{\mathrm{b}}$
}

CORE Discussion Paper 2007/1

\begin{abstract}
The Easter Island tragedy has become an allegory for ecological catastrophe and a warning for the future. In the economic literature the collapse is usually attributed to irrational or myopic behaviors in the context of a fragile ecosystem. In this paper we propose an alternative story involving non-cooperative bargaining between clans to share the crop. Each clan's bargaining power depends on its threat level when fighting a war. The biggest group has the highest probability of winning. A clan's fertility is determined ex ante by each group. In the quest for greater bargaining power, each clan's optimal size depends on that of the other clan, and a population race follows. This race may exhaust the natural resources and lead to the ultimate collapse of the society. In addition to well-known natural factors, the likelihood of a collapse turns out to be greater when the cost of war is low, the probability of succeeding in war is highly responsive to the number of fighters, and the marginal return to labor is not too low. We analyze whether these factors can account for the difference between Easter and Tikopia Islands. The paper also makes a methodological contribution in that it is the first fertility model to include strategic complementarities between groups' fertility decisions.
\end{abstract}

Journal of Economic Literature Classification numbers: J13, O13, J52.

Keywords: Fertility, War, Bargaining Power, Collapse, Natural Resources.

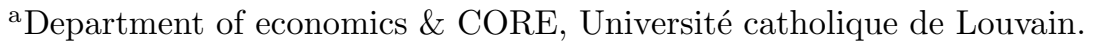
E-mail: delacroix@core.ucl.ac.be.

${ }^{\mathrm{b}}$ Department of economics, Université catholique de Louvain. E-mail: dottori@ires.ucl.ac.be.

${ }^{c}$ The authors acknowledge financial support from the Belgian French speaking community (Grant ARC 03/08-235 "New macroeconomic approaches to the development problem") and the Belgian Federal Government (Grant PAI P5/21, "Equilibrium theory and optimization for public policy and industry regulation"). We thank Thierry Bréchet and the participants at the Conference on Early Economic Development (Copenhagen, August 2006) for valuable comments. We also thank the archeologists and anthropologists Paul Bahn, John Flenley, Thegn Ladefoged and Patrick Kirch for complying with various requests we made.
} 


\section{Introduction}

Easter Island had a rising population and a prosperous civilization until about the XVth century, after which it declined sharply. The most popular sign of that past glory is moai, the enormous statues carved in stone and erected all over the island by the inhabitants. By the XVIIIth century, when the island was discovered by European explorers, the population had been decimated. Easter Island is therefore an example of how a closed system can collapse, but what exactly happened is still an unresolved matter. The question has fascinated historians, sociologists, anthropologists, biologists and - since the seminal article by Brander and Taylor (1998) - economists.

Tikopia is another small island in the Pacific Ocean that provides an interesting contrast. It is similar to Easter Island in many ways, but no collapse occurred and a long-lasting society with a relatively stable population evolved. The population reached 1200 in the XIth century and stayed approximately constant from then on; the environment remains well preserved. Tikopians managed to control population growth (unlike Easter Islanders), thus avoiding the over-exploitation of resources.

Why did Tikopia and Easter Island differ so much, and experience such diverging patterns? In order to identify the central factors which may have led Easter Islanders along the path to collapse, we explore a model where there is interaction among island clans. The expected pay-offs turn out to be affected by the relative size of the groups, thus involving fertility as a strategic choice. In the absence of strong property rights, the clans have to agree how to share the total crop, and this involves non-cooperative bargaining. Bargaining power is affected by the threat of war. We assume that the probability of winning a war depends on the relative size of the group. This is quite a plausible assumption since at that time war-technology was very human-intensive, and we have no reason to believe that the groups differed substantially in their war-technology or any input other than the number of people able to fight. Under certain conditions (which we will identify) there will be a population race, where each group tries to increase its size in order to maintain its bargaining power.

Climatic, geographical and other exogenous factors that cannot explain the different patterns of Easter Island and Tikopia alone, may have prompted the occurrence of a 'population race' on Easter Island, as a consequence of the non-cooperative Nash equilibrium. Such a population race is likely to have brought about over-population and an over-exploitation of resources, even though it emerged as the equilibrium of a 'rational game'.

So far, the economic literature on Easter Island has usually assumed that the dynamics of population growth is mechanistic, following a Malthusian approach according to which fertility is regulated by nutrition. Highly-myopic behavior is often postulated to explain what, from an external viewpoint, looks like irrational over-exploitation of resources leading to the collapse of the society. Here, however, we look at endogenous population dynamics when fertility is a strategic choice for groups. Hence this paper 
also has a methodological contribution in providing the first fertility model with strategic complementarity between fertility decisions across groups. ${ }^{1}$

The paper is organized as follows: in Section 2 the main archeological evidence and the literature on the collapse of small societies are reviewed. In Section 3 the model is described and studied analytically. Section 4 provides numerical simulations of the basic model to account for possible extensions. In Section 5 we discuss the role of different factors on Easter Island and Tikopia. Section 6 concludes with some final remarks.

\section{Historical Evidence and Literature}

Data on Easter Island are available from archaeological studies, ${ }^{2}$ but they generally lack precision. The timing of events is also far from certain, and sources disagree to a considerable extent. The best-accredited theory is that less than 100 people arrived on Easter Island from the Marquesas Islands around CE 400. Thereafter the population began to increase; however according to Cohen (1995) the population remained relatively low until CE 1100, when the increase accelerated. The peak was probably reached around CE 1400-1600 at over 10,000 (perhaps as high as 20,000, see Reuveny and Maxwell (2001), Brander and Taylor (1998)). Figure 1 displays the likely evolution of population over time.

In the XVIth century there was a decline of food consumption with likely episodes of cannibalism around CE 1600 and a big population crash during the XVIIth century. A new religion and a new political order settled down after mid 1600. When Easter Island was discovered by Europeans in CE 1722, estimated population amounted to 3000. At the end of the XVIIIth century a reliable estimate is of about 2000. Then since the XIXth century it is no more correct to consider the island as a closed system as many exogenous shocks happened (kidnapping for slave market, epidemics due to foreign germs, etc.)

As far as natural resources are concerned, when the first settlers arrived island forest was at its carrying capacity. Cutting trees would have begun almost immediately in order to have firewood, land for agriculture, and to make canoas. The process of deforestation was reinforced during the moai-construction period since trees were cut to facilitate the transportation of the statues. The rate of deforestation reached its peak around CE 1400 according to Diamond (2005), and the forest clearance was likely completed by CE 1600 although more precise dates varied locally. In CE 1722 when the Island was discovered by Europeans there was basically no tree. The XVth century is rated to be the period of maximum deforestation. Figure 2 illustrates the deforestation process by reporting the occurrence of forest pollen as a percentage of total pollen over time (from Flenley et al.

\footnotetext{
${ }^{1}$ In his conclusion, Lagerloef (2006) evokes a mechanism close to ours, suggesting that if population size is an input in land acquisition, clans have an extramotive for high fertility.

${ }^{2}$ For more details see Flenley and Bahn (2003), Keegan (1993), Ponting (1991).
} 
(1991)). The deforestation had a clear impact on human life, having "led to leaching and soil erosion, more wind damage, increased soil evaporation and a reduction in crop yields." (Flenley and Bahn (2003), p. 191-2).

Figure 1: Population of Easter Island and Tikopia

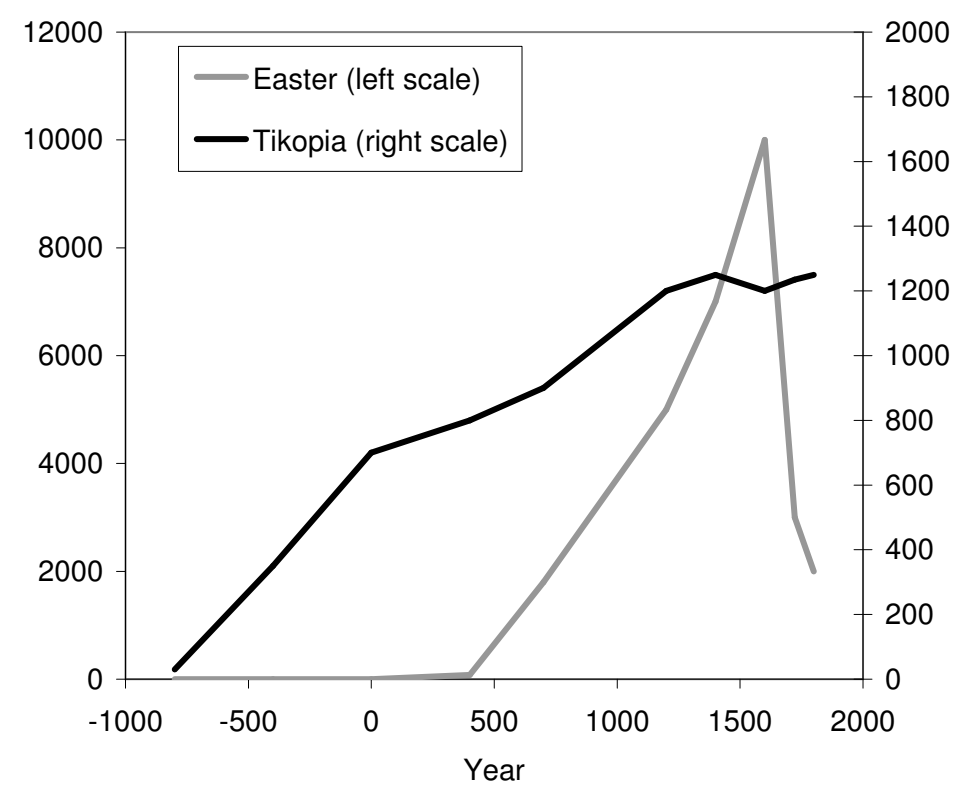

We have also some data on moai-carving. There were 887 statues on Easter Island. Diamond suggests that they were constructed between the XIIth and the XVIth century. The fact that moai-carving ceased around CE 1600 is confirmed by Dalton and Coats, when "the tools of the artisan were replaced with tools of war, such as the mataa (apparently a dagger or spearhead)" 3 .

Tikopia is located in the Pacific Ocean, in the far east of the Solomon Islands; culturally and linguistically its people are of Polynesian stock. ${ }^{4}$ A small group of Polynesians from the East settled on Tikopia about BCE 900 and lived by slash and burn agriculture. Around BCE 100 the economy began to change. Charcoal accumulation ceased, and the people began to rear pigs intensively to compensate for the drastic decline in birds and seafood. After a second wave of immigration, the population reached 1200 and then remained roughly constant (see Figure 1). An important decision was taken around CE 1600: to eliminate pigs, which were becoming too costly to feed in terms of resources.

Over-population was avoided by adopting several practices: celibacy, contraception, abortion, infanticide, sea voyaging by young males, etc. This control of population growth was partly conscious: "On Tikopia [...] people are explicit in saying that their motive for contraception and other regulatory behaviors is to prevent the island from

\footnotetext{
${ }^{3}$ Dalton and Coats (2000) p. 491

${ }^{4}$ For an in-depth study of Tikopian society see Kirch (1986) and Kirch and Yen (1982).
} 
Figure 2: Forest coverage on Easter Island

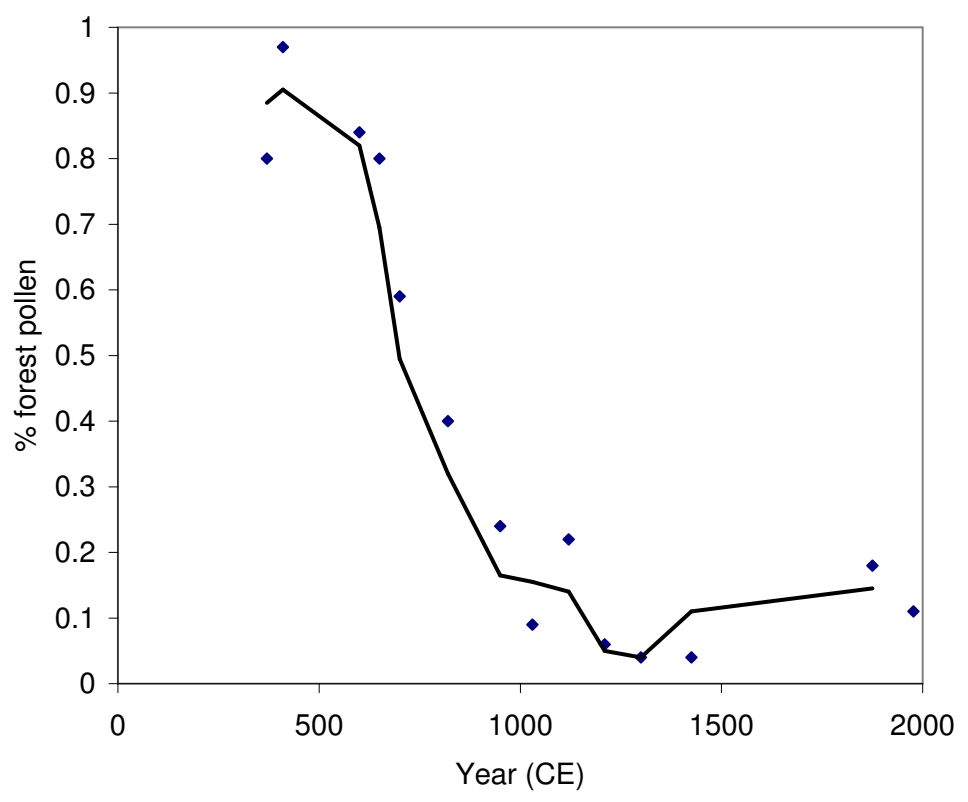

becoming overpopulated [...] The Tikopia chiefs each year carry out a ritual in which they preach an ideal of Zero Population Growth for the island [...] Tikopia parents feel that it is wrong for them to continue giving birth to children of their own once their eldest son has reached marriageable age, or to have more children than a number variously given as four children, or one boy and one girl, or one boy and one or two girls" (Diamond, 2005, p. 290).

Easter Island is considered as an example of how a closed system can collapse, but what exactly happened is still an unresolved matter. The question has fascinated historians, sociologists, anthropologists, biologists and - since the seminal article by Brander and Taylor (1998) - economists. The literature can be broadly divided into two groups: one is based on the dynamic properties of interactions between the laws of motion of renewable resources and exploiters, an idea that goes back to the Lotka-Volterra predator/prey model. The other explicitly assesses the possibility of conflict among groups over resources.

In the first group, the article by Brander and Taylor (1998) explains Easter Island's collapse in a Malthusian-Ricardian fashion: the fertility rate increases with the use of renewable resource (i.e. harvesting), while the increased exploitation of resources necessary to feed people encounters decreasing returns. In this set-up damped cyclical behavior may occur, as well as monotonic convergence. Calibrating parameters in Easter Island's case, Brander and Taylor simulate a bell-shape for the changes in the 
population. ${ }^{5}$

However historical and archaeological studies indicate a sharper decline in population than that predicted by Brander and Taylor. Moreover archaeological studies provide evidence of episodes of cannibalism, movements of islanders into caves and fortified dwellings, fights, the felling of statues, construction of weapons, etc., all of which suggests a sharp and dramatic decline in the civilization. Anderies (2000) and Pezzey and Anderies (2003) introduce a minimum subsistence requirement into Brander and Taylor's model. This allows the implausible assumption of a constant division of time between manufacturing and harvesting whatever the availability of resources to be avoided; in the revised model people stop manufacturing and devote themselves to harvesting when resources become scarce enough, although this means that the remaining resources are depleted faster. Some possible institutional adaptations to prevent collapse, such as an ad-valorem tax and quotas on harvesting are discussed. Erickson and Gowdy (2000) obtain a similar asymmetric decline by introducing capital accumulation of manufactured goods and assuming some substitution between natural and artificial stocks. In this way fertility reacts more slowly initially, because people could use manufactured capital as a partial substitute for natural resources. However at some point the poverty of resources becomes such that this substitution is no longer possible and the population starts to decline abruptly. Tikopia Island is presented as a differently parameterized example, where different institutional habits (i.e. more careful attention to population growth) reduced the natural fertility rate and the rate at which stocks depreciated.

Basener and Ross (2005) assume a logistic growth rate for population dynamics, as well as for resource dynamics. This produces a sudden decrease in population when the total population comes close to the carrying capacity of the eco-system (which depends on the current stock of resources). The role of fertility is highlighted by Reuveny and Decker (2000), who study the effects of different fertility rates on the feast-famine cycle, finding that higher fertility is associated with sharper rises and falls in population. They also examine the effects of technological progress: if technology affects harvesting it tends to exacerbate the feast-famine cycle whereas progress affecting the resource stock tends to moderate the cycle. ${ }^{6}$

Harford (2000) introduces endogenous fertility in the context of renewable resource management, treating the number of children as an optimizing decision. He shows that, in this setting, individuals decide to have children on the basis of a trade off between increasing their own dynasty's utility and devoting part of their income to child rearing, but the cost for the whole society of a greater pressure on the natural resource stock is not internalized. The focus of Harford's paper is in fact on mechanisms to contrast

\footnotetext{
${ }^{5}$ A discrete version of Brander and Taylor's model is provided by Matsumoto (2002) who shows how rich dynamics may arise also in such a framework.

${ }^{6}$ Dalton, Coase, and Badiollah (2005) also study how technological change could have altered the results if Easter Island is used as a metaphor for managing resources in a closed system. The fertility rate still increases with nutrition, but now the feast and famine cycle can be attenuated by technological improvements, encouraged by demographic pressure.
} 
'the tragedy of the commons' (e.g. Pigouvian tax or individual transferable quotas) and not on societal collapses such as that on Easter Island. The fertility choice is driven by bequest motives, and is not strategic.

The other stream of literature deals with conflicting groups. It stems from the evidence of conflicting and competing groups on Easter Island. As Diamond (2005) reports, Easter Island clans were governed by religious-military chiefs who preserved their power through prestige and awe gained by erecting moai. ${ }^{7}$ Property rights were not enforced so that crop sharing was ruled by other institutions, basically bargaining between the chiefs of the various groups.

Reuveny and Maxwell (2001) suggest that two clans may conflict in order to appropriate the total harvest. Each group has to choose its strategy for allocating the group's members between harvesting and conflict, so as to maximize the group's share of the yield, taking into account the choice of the other group. A greater effort in conflict will increase the group's relative share, but the total crop will be negatively affected by the conflict. Population growth in both groups is assumed to increase with nutrition and decrease with conflict, but its laws of motion are not internalized. Since the only objective is current income and the clans are myopic with respect to their growth in population, there is no strategy involving fertility choice. Reuveny and Maxwell argue that this shortsightedness might be appropriate for a primitive society, but there is evidence that Easter Islanders were neither primitive nor completely short-sighted. Think, for example, about building enormous statues: it involves constructing something to be impressive and intimidating for a long time; in the short term it is costly and useless. Rainbird (2002) suggests that Easter Islanders "were not mere unthinking pawns in an environment where they had little choice, but, instead, decision making with the ability and knowledge to manipulate extreme environments for their own ends." Moreover, Tikopians, who were unlikely to have been more developed than Easter Islanders, had a long-term perspective. Even if Easter Island clans were myopic in the long run, they could well have had a multi-period view and the perception that their relative size would have provided them with an advantage in bargaining power.

In a more recent paper Maxwell and Reuveny (2005) compare a non-cooperative outcome with a cooperative one, where groups are not involved in any conflict. They find that the interior steady state is characterized by higher per capita income and higher resource stocks with conflict than without. The intuitive reasoning behind this finding is that when there is no conflict more resources are devoted to harvesting, thus depleting the global stock of resources faster. If conflict comes at a price (for instance, by reducing the amount of natural resources) or if agents behave less short-sightedly, the cooperative setting could bring about a Pareto improvement.

\footnotetext{
${ }^{7}$ When resources became scarcer and social discontent started to spread, the chiefs reacted by trying to increase their prestige in order to keep power. Bigger and bigger moai were built until misery and poverty gave rise to social rebelion and new military leaders ousted the original chiefs. A new religion was established, confirming that great upheavals accompanied the collapse.
} 
Prskawetz, Gragnani, and Feichtinger (2003) use a framework similar to Maxwell and Reuveny (2005), but they also account for the possible harmful effects of conflict on death rates and the growth rate of resources and perform a local bifurcation analysis, focused in particular on the parameters related to such feedback effects. They find that sustainability requires stabilizing feedback mechanisms to become active at an early stage. In their model conflict is postulated to arise when the natural resource stock per capita falls below some threshold, and so it does not explicitly result in a strategic equilibrium. A model of rational conflict is provided by Lasserre and Souberyan (2003) who consider the conditions under which groups decide how to allocate time between production and conflict in a tragedy of the commons context and whether to specialize in one or other activity. They find that multiple equilibria may arise, both interior and at the extremes. In their model, however, population growth is not analyzed.

\section{The Model}

In this section we will develop a stylized model to show how the main mechanism we put forward can explain an environmental collapse. We consider an overlapping generations framework where agents live for two periods. Every agent belongs to a clan. In each period, the timing of decisions is as follows. Each clan chooses its fertility rate, taking the other's fertility rate as given, and having perfect foresight. A Nash(-Cournot) equilibrium in fertility rates follows, characterized by a match between the strategy actually played and the strategy expected by the other group. The crop is then shared, following a non-cooperative bargaining process between clans.

\subsection{Preferences and Technology}

For the sake of simplicity we assume that there are only two clans, and that all individuals belong either to one or the other clan, with no possibility of changing clan membership. Group $i$ at time $t$ consists of $N_{i, t}$ adults. In the first period the adults are young, they work, they support their parents' consumption and they make fertility choices; in the second part of their life they consume what their children provide for them. A representative adult belonging to group $i$ receives utility from both periods of consumption and bears a disutility cost from child rearing. At this stage we assume that households are risk neutral, i.e. preferences are represented by a linear utility function:

$$
U_{i, t}=c_{i, t}+\beta d_{i, t+1}-\lambda n_{i, t}
$$

where $c_{i, t}$, and $d_{i, t+1}$ are the first and second period consumption respectively, $n_{i, t}$ is the number of children per adult in Group $i$ at time $t, \beta>0$ is the psychological discount factor, and $\lambda>0$ is the marginal disutility of child rearing. The case of risk averse agents is analyzed in Section 4.1. 
Supporting parents costs a fraction $\tau /\left(1+n_{i, t-1}\right)$ of young adults' total income $y_{i, t}$. To simplify we assume that $\tau \in(0,1)$ results from an exogenous social norm. ${ }^{8}$ Hence the parent receives a total of

$$
\tau \frac{n_{i, t-1}}{\left(1+n_{i, t-1}\right)} y_{i, t}
$$

This formulation introduces the idea that each additional child will bring some additional resources to the parents, but the returns are not constant, since the fraction each child pays decreases with the number of siblings. Therefore the budget constraint in the first period is:

$$
c_{i, t}=\left(1-\frac{\tau}{1+n_{i, t-1}}\right) y_{i, t}
$$

In the second part of their life, agents are economically supported by their children. Hence the budget constraint is

$$
d_{i, t+1}=n_{i, t} \frac{\tau}{1+n_{i, t}} y_{i, t+1}
$$

The population evolves for each group according to the law of motion

$$
N_{i, t+1}=n_{i, t} N_{i, t}
$$

In each period, crop $Y_{t}$ is obtained according to the production function

$$
Y_{t}=A\left(R_{t}\right) L^{\alpha}\left(N_{1, t}+N_{2, t}\right)^{1-\alpha}
$$

where $L$ is the fixed amount of land, ${ }^{9}$ and $A\left(R_{t}\right)$ is the TFP which depends on the stock of natural resources $R_{t}$ available at time $t$. The function $A()$ may reflect exogenous conditions determining differences between productivity on Tikopia and Easter Island.

The dynamics of the stock of resources is taken from Matsumoto (2002) as:

$$
R_{t+1}=\left(1+\delta-\delta R_{t} / K-b\left(N_{1, t}+N_{2, t}\right)\right) R_{t}
$$

where $K>0$ is the carrying capacity, i.e. the maximum possible size of the stock of resources, $\delta>0$ is the intrinsic growth rate of natural resources, and $b>0$ is a coefficient weighting the effect of human absorption of resources. Equation (5) results

\footnotetext{
${ }^{8}$ In the literature on old-age support (Ehrlich and Lui 1991), the compensation rate $\tau$ is determined through self-enforcing implicit contracts. At equilibrium, the value of $\tau$ typically depends on longevity and the availability of capital markets.

${ }^{9}$ Since the amount of land is fixed we can set its value at 1 without loss of generality.
} 
from the difference between a logistic 'natural' growth rate and a negative human impact on resources. ${ }^{10}$ It has the following property:

$$
\lim _{t \rightarrow \infty} N_{1, t}+N_{2, t}=0 \Rightarrow \lim _{t \rightarrow \infty} R_{t}=K
$$

Let us denote by $\theta$ Group 1's share of the total crop. The representative adult's income can be written as a function of his or her clan's share as:

$$
\begin{aligned}
& y_{1, t}=\theta_{t} Y_{t} / N_{1, t} \\
& y_{2, t}=\left(1-\theta_{t}\right) Y_{t} / N_{2, t} .
\end{aligned}
$$

In the absence of strong property rights and input markets, groups bargain to reach an agreement on crop-sharing: if they did not a war could take place. The bargaining power of each group is affected by its relative size. Therefore under perfect foresight each group has an incentive to increase its fertility in order to increase its threat level in the future. Before studying the bargaining problem analytically let us discuss the two main assumptions on which the mechanism we propose is built.

First, fertility is fixed before the bargaining begins, as a social norm. It may be questioned whether it is not too extreme to assume that clans control their members' fertility. In our framework there is no division between the subjects who are involved in bargaining (the clans) and those who actually have children (all agents are perfectly equal within the clans). In reality the number of children could in fact have been to some extent a social norm: Erickson and Gowdy (2000) refer to archaeological evidence for Tikopia in support of "the adoption of cultural beliefs that incorporated the ethic of zero population growth" ${ }^{11}$ Diamond (2005) reports the highly hierarchical and centralized structure of clans on Easter Island. ${ }^{12}$

Second, the probability of success in war is ultimately determined by the relative number of individuals able to fight, i.e. young people: when two groups conflict, using basically the same labor-intensive war technology, it is plausible to expect that the bigger group is more likely to win. ${ }^{13}$ There is good evidence for episodes of conflict on Easter Island (Ponting (1991), Keegan (1993)), but Diamond (2005) also reports clashes on Tikopia.

\footnotetext{
${ }^{10} \mathrm{An}$ analogous specification in continuous time is common to almost the whole literature reviewed in Section 2 (see, for instance, Brander and Taylor (1998), Pezzey and Anderies (2003), Dalton and Coats (2000) and Reuveny and Maxwell (2001)).

${ }^{11}$ See Erickson and Gowdy (2000) pp. 350, 351. The 'fono', an annual address by Tikopian chiefs, is described as a proclamation encoding the idea of zero population growth. Section 2 mentions several indications of conscious control over population growth.

${ }^{12}$ The chief was a religious and military leader with great power, who needed to retain his prestige through successful competition with other clans.

${ }^{13}$ Reuveny and Maxwell (2001), Lasserre and Souberyan (2003), Maxwell and Reuveny (2005) and Prskawetz, Gragnani, and Feichtinger (2003) all consider a labor-intensive war technology.
} 


\subsection{The Bargaining Problem}

The outcome of non-cooperative bargaining can be modeled by maximizing a Nash product (Binmore, Rubinstein, and Wolinsky 1986):

$$
\left(U_{1, t}-\bar{U}_{1, t}\right)^{\gamma}\left(U_{2, t}-\bar{U}_{2, t}\right)^{1-\gamma}
$$

where $U_{i, t}$ is the pay-off of Group $i, \bar{U}_{i, t}$ is the fall-back pay-off for Group $i$ if no agreement is reached, and $\gamma \in(0,1)$ is a parameter for the possible residual asymmetries in bargaining power. The parameter $\gamma$ may represent exogenous asymmetries in bargaining positions, for instance the quality of the land occupied by each group. ${ }^{14}$

Using equations (1), (2) and (3), the clans' indirect utilities are respectively:

$$
\begin{aligned}
U_{1, t} & =\left(1-\frac{\tau}{1+n_{1, t-1}}\right) \frac{\theta_{t} Y_{t}}{N_{1, t}}+\beta \frac{n_{1, t} \tau}{1+n_{1, t}} \frac{\theta_{t+1} Y_{t+1}}{N_{1, t+1}}-\lambda n_{1, t} \\
U_{2, t} & =\left(1-\frac{\tau}{1+n_{2, t-1}}\right) \frac{\left(1-\theta_{t}\right) Y_{t}}{N_{2, t}}+\beta \frac{n_{2, t} \tau}{1+n_{2, t}} \frac{\left(1-\theta_{t+1}\right) Y_{t+1}}{N_{2, t+1}}-\lambda n_{2, t} .
\end{aligned}
$$

The fall back pay-off $\bar{U}_{i, t}$ is represented by the utility of a failed agreement. If the parties do not come to an arrangement they fight. In other words we can see the emergence of war as a threat to induce compliance. When a war happens the income is an expected value, since it depends on the probability of the group of winning the war. We allow for the possibility that, during the war, a fraction $\omega \in[0,1)$ of the total crop is wasted. This is likely to occur because fighting often brings about a depletion of resources, or missed production; at the very least the resources are consumed in fighting and so do not provide the usual utility. Moreover, we assume that when a clan wins a war, it appropriates the total crop and that war entails no human loss. ${ }^{15}$

We denote the probability of Group 1 winning the war by $\pi_{t}$. We assume that the form of the function $\pi_{t}=p\left(N_{1, t}, N_{2, t}\right)$ relating the winning probability to group sizes satisfies the properties specified in an axiomatic approach by Skaperdas (1996) for contest success functions:

- being positive, between zero and one, and the sum of all groups' probabilities adding up to one (conditions for a probability distribution function);

\footnotetext{
${ }^{14}$ Easter Island land was divided among clans in a radial way, but the quality of land was not uniform. Nevertheless there is no reason to believe that these differences alone enabled one group to achieve a clear and definitive success in taking possession of the crop.

${ }^{15}$ This assumption allows the extreme possibility of the extermination of a group (which was probably not the intention of the clans and was also unrealistic in such societies, considering the available weapons and war technology) to be avoided. There is evidence (see Owsley, Will, and Ousley (1994)) that struggles very seldom entailed mortal wounds, given the kind of weapons used, and few fatalities were attributable directly to violence. Hence we assume, like Maxwell and Reuveny (2005), that war does not imply a cost in terms of human life. Since war plays the role of a fall-back outcome that never occurs in the bargaining equilibrium, permitting human loss would simply alter the bargaining power quantitatively without adding substantive insights.
} 
- being increasing with the groups' own contest effort, and decreasing with the other groups' efforts;

- being anonymous, in the sense that the outcome only depends on the relative efforts and if every group makes the same effort in the conflict then their probability of winning is equal;

- contests among smaller numbers of groups are qualitatively similar to contests among a large number of groups; ${ }^{16}$

- homogeneity, in the sense that multiplying each effort by the same amount does not affect the probability of winning.

Skaperdas (1996) shows that

$$
p\left(N_{1, t}, N_{2, t}\right)=\frac{N_{1, t}^{\mu}}{N_{1, t}^{\mu}+N_{2, t}^{\mu}} \in(0,1)
$$

is the only continuous function to satisfy all these properties. The parameter $\mu \geq 1$ is related to the sensitivity of the probability of winning a war to the size of the clan. It has to be greater than 1 to guarantee the convexity of the maximization problem. The higher $\mu$, the greater the influence of the size of the group, so that $\mu$ captures the decisiveness of groups' relative size. The main implication of this is that the ratio of winning probabilities of any two players depends on the ratio of their efforts. ${ }^{17}$ An increase in $\mu$ has a positive impact on $\pi_{t}$ if and only if $N_{1, t}>N_{2, t}$. Here we have:

$$
\frac{\partial p}{\partial \mu}=\frac{\mu N_{1, t}^{\mu} N_{2, t}^{\mu}}{\left(N_{1, t}^{\mu}+N_{2, t}^{\mu}\right)^{2}} \ln \left(\frac{N_{1, t}}{N_{2, t}}\right) .
$$

The fall back utility of Group 1 can be written as:

$$
\bar{U}_{1, t}=\pi_{t}\left[\left(1-\frac{\tau}{1+n_{1, t-1}}\right) \frac{(1-\omega) Y_{t}}{N_{1, t}}\right]+\beta \frac{n_{1, t} \tau}{1+n_{1, t}} \frac{\theta_{t+1} Y_{t+1}}{N_{1, t+1}}-\lambda n_{1, t} .
$$

\footnotetext{
${ }^{16}$ With only two groups this property is trivial, but it can be proved to hold if a larger number of groups is involved.

${ }^{17}$ An alternative functional form that is frequently used is the logistic: $\pi=1 / \exp \left[\mu\left(F_{2}-F 1\right)\right]$ where $F_{i}$ denotes the effort made by Group $i$. This formulation implies that it is the difference between efforts that determines the probability of success. Notice that if we take a logarithmic effort function $\left(F\left(N_{i}\right)=\ln \left(N_{i}\right)\right)$ we still end up with Equation(6). The issue of the linearity of effort to the number of combatants is not central to our model: taking a linear effort function and probability of success, or taking a logarithmic effort function and a logistic probability of success both yield Equation(6), which turns out to be suitable for analytical study since it allows useful simplifications. Such simplifications are not possible if we consider a linear effort function and a logistic probability. Although Hirshleifer (1991) argues that such a form matches some empirical data on battles better, we prefer to retain the formulation in Equation (6) for several reasons: as Skaperdas (1996) points out, such evidence is far from being conclusive; the homogeneity axiom is not satisfied; some outcomes may be counter-intuitive; and, last but not least, the possibility of in-depth analytical study would be complicated without providing additional insights.
} 
Notice that fertility has already been chosen when groups bargain, therefore the disutility of child-rearing is not affected by the outcome of the bargaining. Second period consumption depends on expectations about the next period agreement $\left(\theta_{t+1}\right)$ and output $\left(Y_{t+1}\right)$. Perfect foresight is assumed. Notice that the outcome of the bargaining today has no influence on the bargaining tomorrow. The utility net of fall-back is:

$$
\begin{aligned}
& U_{1, t}-\bar{U}_{1, t}=\left(1-\frac{\tau}{1+n_{1, t-1}}\right)\left(\theta_{t}-\pi_{t}(1-\omega)\right) \frac{Y_{t}}{N_{1, t}} \\
& U_{2, t}-\bar{U}_{2, t}=\left(1-\frac{\tau}{1+n_{2, t-1}}\right)\left(1-\theta_{t}-\left(1-\pi_{t}\right)(1-\omega)\right) \frac{Y_{t}}{N_{2, t}} .
\end{aligned}
$$

Abstracting from constant terms, the net utilities become

$$
\begin{aligned}
& U_{1, t}-\bar{U}_{1, t}=\theta_{t}-\pi_{t}(1-\omega) \\
& U_{2, t}-\bar{U}_{2, t}=1-\theta_{t}-\left(1-\pi_{t}\right)(1-\omega) .
\end{aligned}
$$

Using these values the bargaining problem simplifies to:

$$
\theta_{t} \equiv \arg \max \left[\theta_{t}-\pi_{t}(1-\omega)\right]^{\gamma}\left[1-\theta_{t}-\left(1-\pi_{t}\right)(1-\omega)\right]^{1-\gamma} .
$$

Proposition 1 (Bargaining Outcome) The bargaining share of the crop for Clan 1 is:

$$
\theta_{t}=\gamma \omega+\frac{N_{1, t}^{\mu}}{N_{1, t}^{\mu}+N_{2, t}^{\mu}}(1-\omega)
$$

The following comparative statics results are derived:

$$
\begin{aligned}
& \frac{\partial \theta_{t}}{\partial \gamma}=\omega \quad \geq 0 \\
& \frac{\partial \theta_{t}}{\partial \omega}=\gamma-\pi_{t} \quad \geq 0 \quad \text { iff } \pi_{t} \leq \gamma \\
& \frac{\partial \theta_{t}}{\partial \mu}=\frac{N_{1, t}^{\mu} N_{2, t}^{\mu}(1-\omega) \ln \left(\frac{N_{1, t}}{N_{2, t}}\right)}{\left(N_{1, t}^{\mu}+N_{2, t}^{\mu}\right)^{2}} \geq 0 \quad \text { iff } N_{1, t} \geq N_{2, t} .
\end{aligned}
$$

Proof: The first order condition for Problem (7) yields Equation (8). The second order condition for a maximum, $\left[-(1-\gamma) \gamma \omega^{2}\right]^{-1}<0$, is satisfied.

The effect of $\gamma$ on $\theta_{t}$ is unambiguously positive: when it increases the asymmetries in bargaining change in favor of Clan 1 thus strengthening its bargaining position. An increase in the dead-weight loss $\omega$ reduces the fall back of both groups, but in an asymmetric way depending on the groups' relative size. As Equation (8) shows, $\theta$ turns out to be a weighted sum of the exogenous contractual power $\gamma$ and the endogenous force, due to the likelihood of winning the war, $\pi_{t}$; therefore an increase in the relative weight of the former increases $\theta_{t}$ if and only if $\gamma>\pi_{t}$. Finally an increase in the sensitivity of the probability of victory to the numbers of fighters involved determines the advantage of the group with the bigger size. 


\subsection{The Fertility Choice}

Let us now turn to the choice of fertility made by adults at time $t$. The variable part of the utility, for Clans 1 and 2 respectively, is given by:

$$
\frac{\beta \tau n_{1, t}}{1+n_{1, t}}\left[\gamma \omega+\frac{\left(N_{1, t} n_{1, t}\right)^{\mu}(1-\omega)}{\left(N_{1, t} n_{1, t}\right)^{\mu}+\left(N_{2, t} n_{2, t}\right)^{\mu}}\right] \frac{A\left(R_{t+1}\right)\left(N_{1, t} n_{1, t}+N_{2, t} n_{2, t}\right)^{1-\alpha}}{N_{1, t} n_{1, t}}-\lambda n_{1, t}
$$

and

$$
\frac{\beta \tau n_{2, t}}{1+n_{2, t}}\left[1-\gamma \omega-\frac{\left(N_{1, t} n_{1, t}\right)^{\mu}(1-\omega)}{\left(N_{1, t} n_{1, t}\right)^{\mu}+\left(N_{2, t} n_{2, t}\right)^{\mu}}\right] \frac{A\left(R_{t+1}\right)\left(N_{1, t} n_{1, t}+N_{2, t} n_{2, t}\right)^{1-\alpha}}{N_{2, t} n_{2, t}}-\lambda n_{2, t}
$$

At this point it is worth noting the channels through which endogenous fertility affects utility. There are two kinds of benefits from having more children: a higher old age support and a strategic motive which operates through an increase in the probability of succeeding in war, and hence through the clan's threat-value in bargaining. On the other hand there are two costs from having children: a direct disutility cost from rearing them, and greater pressure on crops in the next period, as the crops have to be divided among more people.

The first order conditions for Clans 1 and 2 are given by:

$$
\begin{gathered}
\frac{1-\omega}{1+n_{1, t}} \frac{\partial \pi_{t+1}}{\partial n_{1, t}}+\frac{(1-\alpha) N_{1, t} \theta_{t+1}}{\left(1+n_{1, t}\right)\left(N_{1, t} n_{1, t}+N_{2, t} n_{2, t}\right)}=\frac{\theta_{t+1}}{\left(1+n_{1, t}\right)^{2}}+\frac{\lambda}{\beta \tau} \frac{N_{1, t}}{Y_{t+1}} \\
-\frac{1-\omega}{1+n_{2, t}} \frac{\partial \pi_{t+1}}{\partial n_{2, t}}+\frac{(1-\alpha) N_{2, t}\left(1-\theta_{t+1}\right)}{\left(1+n_{2, t}\right)\left(N_{1, t} n_{1, t}+N_{2, t} n_{2, t}\right)}=\frac{1-\theta_{t+1}}{\left(1+n_{2, t}\right)^{2}}+\frac{\lambda}{\beta \tau} \frac{N_{2, t}}{Y_{t+1}}
\end{gathered}
$$

where $\theta_{t+1}$ is obtained from Equation (8), while from Equations (4) and (6) we have

$$
\pi_{t+1}=\frac{\left(N_{1, t} n_{1, t}\right)^{\mu}}{\left(N_{1, t} n_{1, t}\right)^{\mu}+\left(N_{2, t} n_{2, t}\right)^{\mu}} .
$$

At optimum the marginal benefit from increasing fertility (the l.h.s. of Equations (9) and (10)) equals the marginal cost (the r.h.s.). The benefit is represented by the increase in consumption in the second period, due to the larger clan's share and the larger total contribution of their offspring; the cost is represented by the reduction in crop per capita (due to decreasing marginal returns) and the cost of child rearing.

Each group's optimal fertility rate turns out to depend on expectations about the other group's fertility: in this sense we can talk of fertility reaction functions. We assume that when clans choose their own fertility rate they take the other group's one as given, i.e. they behave á la Cournot. A necessary condition for a population race to occur is that fertility reaction functions must have a positive slope, so that it is best for each group to respond to increases in the other group's fertility rate by having more children itself.

Although there is no explicit solution to Equations 9) and (10), we can characterize the solution for a particular parameter configuration as satisfying 
Assumption 1 Parameters satisfy $\mu=1, \omega=0, \lambda=0$, and $\alpha=1$.

Assumption 1 tells us that $\pi_{t}$ is equal to the proportion of fighters who belong to Group 1 , there is no dead-weight loss with war and no disutility from child-rearing. Finally $\alpha=1$ means that at every period the island yields a given amount of food depending solely on the stock of natural resources, e.g. coconuts. In this scenario Proposition 2 holds:

\section{Proposition 2 Under Assumption 1:}

- the fertility reaction functions have positive slopes;

- the Nash equilibrium is

$$
n_{1, t}^{*}=\sqrt[3]{\frac{N_{2, t}}{N_{1, t}}}, \quad n_{2, t}^{*}=\sqrt[3]{\frac{N_{1, t}}{N_{2, t}}}
$$

- the Nash equilibrium is stable. ${ }^{18}$

Proof: Setting $\omega=0, \mu=1, \lambda=0, \alpha=1$ in Equations (9) and (10) we obtain the reaction functions

$$
n_{1, t}=\sqrt{\frac{N_{2, t}}{N_{1, t}} n_{2, t}} \quad \text { and } \quad n_{2, t}=\sqrt{\frac{N_{1, t}}{N_{2, t}} n_{1, t}}
$$

which show that the best fertility rate for each group is to increase as the other group's fertility increases. At the Nash equilibrium, there is no incentive for either group to change its fertility rate, given the other group's fertility rate; this amounts to solving the system in Equation (12), which yields the results in Equation (11). This solution represents a maximum as

$$
U_{i}^{\prime \prime}-\frac{2 A N_{j, t}\left(2 N_{i, t}+\sqrt[3]{\frac{N_{i, t}^{4}}{N_{j, t}}}+\sqrt[3]{N_{i, t}^{2} N_{j, t}}\right) R_{t+1} \beta \tau}{\left(N_{j, t}+\sqrt[3]{N_{i, t}^{2} N_{j, t}}+2 \sqrt[3]{N_{i, t} N_{j, t}^{2}}\right)^{3}}<0 .
$$

At equilibrium the slopes of the reaction functions are

$$
\frac{\partial n_{i, t}}{\partial n_{j, t}}=\frac{1}{2}\left(\frac{N_{j, t}}{N_{i, t}}\right)^{2 / 3} .
$$

To demonstrate the stability of the Nash equilibrium, we compute the inverse reaction function of Group 2 as $n_{1, t}=n_{2, t}^{2}\left(N_{2, t} / N_{1, t}\right)$. The slope of this curve at equilibrium

\footnotetext{
${ }^{18}$ The stability of the Nash equilibrium should not be confused with the concept of (dynamic) stability which is used in Section 3.4. The Nash equilibrium is stable when small changes in the strategy of one clan lead to a situation where the clan which did not change has no better strategy than its original one (i.e. the original reaction function) and the clan which did change is now using a strategy which is worse. Intuitively, we can see that, in the neighborhood of an equilibrium, adjustments along the reaction functions converge toward the original equilibrium (see Hahn (1962)).
} 
is $\left(N_{1, t} / N_{2, t}\right)^{2 / 3}$, which is always greater that for Group 1. This ensures that in the $\{n 2, n 1\}$ space Group 1's reaction function intersects Group 2's from above and the equilibrium is stable. The equilibrium can be reached through adjustments along the reaction functions.

The finding that fertility reaction functions have positive slopes means that there is a strategic complementarity between group sizes, and therefore between the groups' fertility rates as implied by the population race mechanism. It is interesting to observe how the fertility changes if we allow the parameters to be perturbed. The results are summarized in Corollary 1 and are illustrated graphically in Figure 3.

Corollary 1 In the neighborhood of the Nash equilibrium obtained under Assumption 1, the following comparative statics hold:

$$
\begin{aligned}
& \frac{\partial n_{i, t}}{\partial \omega}<0,<n_{i, t} \\
& \frac{\partial \mu}{\mu}>0, \\
& \frac{\partial n_{i, t}}{\partial \lambda}<0, \\
& \frac{\partial n_{i, t}}{\partial \alpha}<0 .
\end{aligned}
$$

Proof: $\quad$ See Appendix A.1.

We observe that equilibrium fertility decreases with $\omega$. Indeed, when a war has a high potential cost the importance of military power in determining the outcome of the bargaining decreases, and this reduces the strength of the strategic motive for fertility. If $\mu$ increases, the fertility rates at equilibrium also increase: when the bargained share is equal to the probability of success, then, if this probability becomes more sensitive to the relative size of the clans, it is best to increase the size of each clan. As expected, an increase in the disutility of child rearing decreases fertility because having children entails a (greater) disutility cost. Finally, when returns to labor are greater ( $\alpha$ is lower) it is optimal to increase fertility because the negative impact on crop per capita is less.

Notice that, when evaluating the marginal effects under Assumption 1, $\beta, \tau$, and $\gamma$ have no effect. If we evaluate their effects in different configurations, further insights can be gained as long as the reaction functions continue to have positive slopes. In particular we have Corollary 2, below. 
Corollary 2 If the fertility reaction functions have positive slopes the following comparative statics hold:

$$
\begin{aligned}
\frac{\partial n_{i, t}}{\partial \beta} & \geq 0, \\
\frac{\partial n_{i, t}}{\partial \tau} & \geq 0, \\
\text { if }\{\alpha=1\} & \frac{\partial n_{i, t}}{\partial \gamma} \leq[\geq] \quad 0 \quad \text { with } i=1[2], \\
\text { if }\{\alpha=1, \mu=1\} \quad \frac{\partial n_{i, t}}{\partial A_{t+1}} & \geq 0 .
\end{aligned}
$$

Proof: $\quad$ See Appendix A.2.

Both $\tau$ and $\beta$ are associated with greater importance of the role of children as old-age support. Therefore they have the common effect of making the cost of child rearing, and hence of enhancing fertility, relatively more bearable. ${ }^{19}$ The parameter $\gamma$ for the exogenous contractual asymmetries in favor of Group 1 has a negative impact on the optimal fertility of Group 1 and a positive impact on the fertility of Group 2. In other words, when the exogenous contractual strength of one group increases, it prefers to reduce its own fertility, whereas the fertility of the other group increases. The reason why this happens can be seen as a substitution effect: ceteris paribus, the same bargained share can be achieved with a lower military threat, and since the military threat comes at a cost, the more powerful group chooses a lower fertility rate, whereas the other group has to compensate by investing in the other source of bargaining power (i.e. the threat of war). ${ }^{20}$ Total factor productivity $A_{t+1}$ is not a parameter as it depends on the current stock of resources; nevertheless it is exogenous to clans' fertility choices and can be dealt with in a comparative statics set-up. It has a positive effect that can be seen as an income effect, making more children affordable for a given disutility of child rearing. ${ }^{21}$

Figure 3 summarizes Corollaries 1 and 2. It is worth remarking that Corollary 1 evaluates the parameters at the Nash equilibrium under Assumption 1, whereas the parameters in Corollary 2 have zero effect at that configuration, but have the effects already discussed when evaluated elsewhere (as long as the fertility reaction functions have positive slopes and the specific restrictions given in Corollary 2 are satisfied).

\footnotetext{
${ }^{19}$ They only have zero effect when such a cost is not present.

${ }^{20}$ Notice that when $\omega=0$, the bargained share is unaffected by $\gamma$ and accordingly this parameter has no effect on fertility rates.

${ }^{21}$ When $\lambda=0$ we have a zero effect.
} 
Figure 3: Reaction functions $\left(r_{1}, r_{2}\right)$ and comparative statics
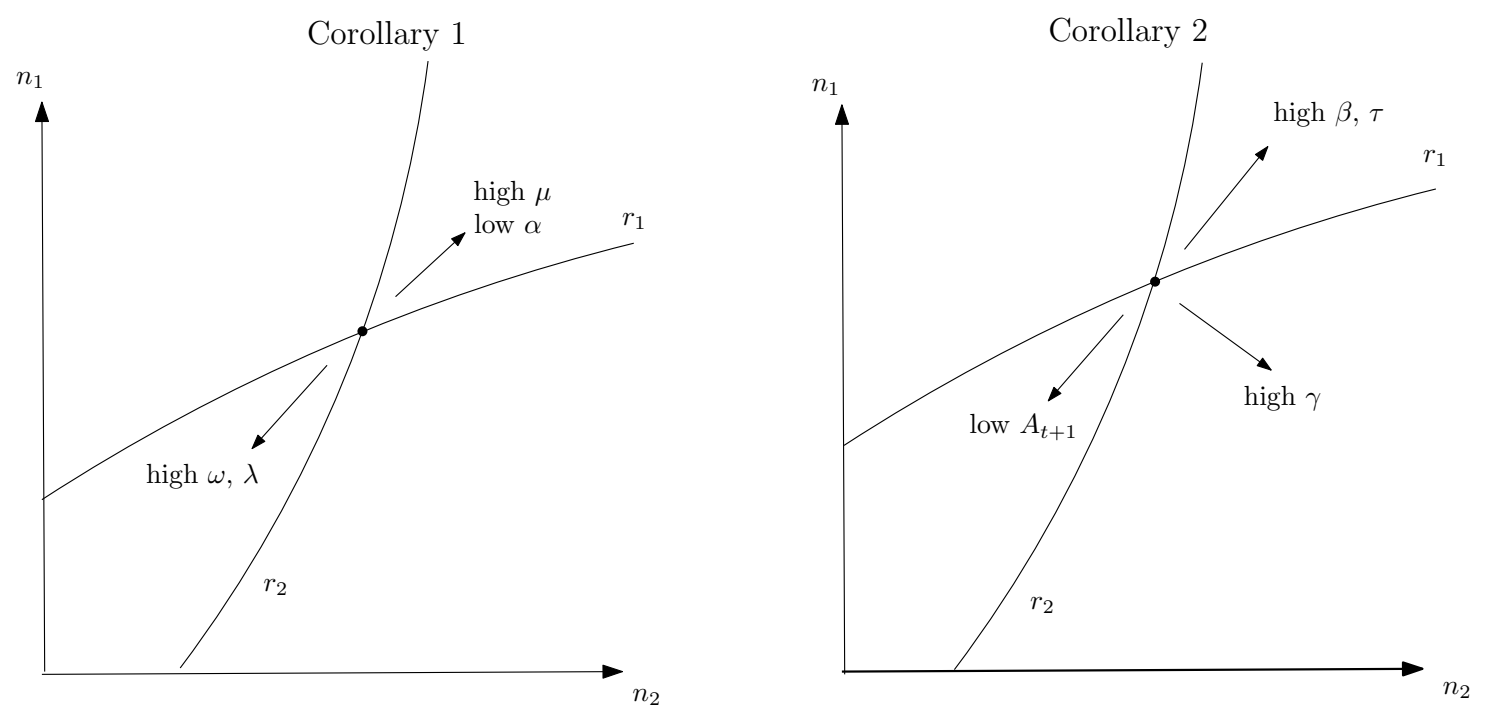

\subsection{Dynamics}

We can now assess the dynamics of the model under Assumption 1. The dynamics of the population is obtained by inserting Equation (11) into Equation (4) to give

$$
N_{i, t+1}=N_{i, t} \sqrt[3]{\frac{N_{j, t}}{N_{i, t}}}
$$

Denoting $\ln x$ by $\hat{x}$, the population dynamics is determined by a system of two linear difference equations:

$$
\hat{N}_{i, t+1}=\hat{N}_{i, t} 2 / 3+\hat{N}_{j, t} / 3 \text {. }
$$

The solution is given by

$$
\hat{N}_{i, t}=\frac{\hat{N}_{1,0}+\hat{N}_{2,0}}{2}+\frac{3^{-t}}{2}\left(\hat{N}_{i, 0}-\hat{N}_{j, 0}\right)
$$

and at steady state, the population of the two clans is equal and given by the geometric average of the two initial population levels:

$$
\bar{N}_{i}=\bar{N}_{j}=\sqrt{N_{1,0}} \sqrt{N_{2,0}} .
$$

The dynamics of the stock of resources is provided by Equation (5), which has a steady state

$$
\bar{R}=K\left(1-\frac{b\left(\bar{N}_{i}+\bar{N}_{j}\right)}{\delta}\right)
$$

A positive steady state exists if and only if $\bar{N}_{i}+\bar{N}_{j}<\delta / b$. We can write this as a condition on the initial populations to give the following proposition: 


\section{Proposition 3}

- If a strictly positive steady state for resources exists, then it is stable.

- Under Assumption 1:

- a positive stable steady state exists if and only if the initial populations are not too high:

$$
2 b \sqrt{N_{1,0}} \sqrt{N_{2,0}}<\delta .
$$

- at steady state $\bar{\pi}=1 / 2$ and $\bar{\theta}=1 / 2$.

Proof: $\quad$ The steady state for Equation (14) is strictly positive if and only if

$$
\frac{b\left(N_{i}+N_{j}\right)}{\delta}<1
$$

The first derivative of Equation (5) evaluated at the steady state reads $1-\delta+b\left(N_{i}+N_{j}\right)$. This is less than 1 if Condition (15) holds. Hence the positive steady state is asymptotically stable. This proves the first point.

Inserting Equations (13) into Equation (14) we can reduce the condition for the convergence of resources to a strictly positive long-run level to a condition for the initial population (see above). This proves the second point.

Finally, when $\omega=0, \theta_{t}=\pi_{t}$. At steady state the two groups have the same population, and so $\bar{\pi}=1 / 2$. Therefore we also have $\bar{\theta}=\bar{\pi}=1 / 2$.

With Assumption 1, the ecosystem can sustain a long run equilibrium providing the initial population is not too high; in other circumstances an environmental trap occurs. The dynamics for more general cases, and the role of factors affecting the occurrence of an environmental collapse, are studied through numerical simulations in Section 4.3. At this stage it is possible to see from Equation (5) that a higher population uses more resources, and from Equation (14) that the occurrence of an environmental trap depends on the long run dynamics of the total population. Therefore, any change in parameters which has the effect of increasing equilibrium fertility rates also has the effect of increasing the likelihood of an environmental trap. This implies that two similar societies with different $\mu$ 's may end up in very different situations: the one where $\mu$ is low may experience a moderate population growth and so achieve a long run stable equilibrium, whereas the society where $\mu$ is high may be doomed to collapse.

\section{Numerical Simulations and Robustness Analysis}

In the previous section we derived some theoretical results for a specific configuration of the parameters. In this section we investigate whether these results still hold when the 
parameters take different values. We are also interested in knowing whether adopting a more general utility function would alter the results.

In the first subsection we consider the fertility problem for one generation: we numerically compare the benchmark model studied analytically in Section 3.3 with that resulting from a different setting of the parameters. In the second subsection we analyze the effect of introducing risk aversion instead of risk neutrality. Finally the dynamics of resources and population are considered. We study the combinations of $\mu$ and $\omega$ under which a collapse may arise and we assess how they are affected by changes in the other parameters.

\subsection{The Nash Equilibrium}

Let us begin by setting some values for the parameters, which are summarized in Table 1. A few words on these values: $\gamma=1 / 2$ means that there is no exogenous asymmetry in the bargaining process; setting $\tau=0.8$ implies that, for instance, young adults with two siblings support their parents with $20 \%$ of their income, and the parent receives a total of $60 \%$ of the income of a young adult in this group. For the sake of simplicity the discount factor $\beta$ is set to 1 . The returns parameter $\alpha$ and the coefficient on child disutility $\lambda$ are set to 1 and 0 respectively, as in Assumption 1. ¿From Section 3.3 we know that fertility rates are increased (decreased) by a lower $\alpha$ (a greater $\lambda$ ). We take initial population levels of 90 and 100 respectively, the fact that Group 2 is bigger than Group 1 implying that it is more likely to win if there is a conflict. The total factor productivity $A()$ depends on the stock of resources. For the sake of simplicity we assume $A\left(R_{t}\right)=A R_{t}$ and set $A=10$.

Table 1: Benchmark parametrization

\begin{tabular}{ccccccccccc}
\hline \hline$\gamma$ & $\lambda$ & $\alpha$ & $\tau$ & $\beta$ & $A$ & $N_{1, t}$ & $N_{2, t}$ & $\delta$ & $b$ & $K$ \\
.5 & 0 & 1 & .8 & 1 & 10 & 90 & 100 & .08 & $1.2 \cdot 10^{-4}$ & 12000 \\
\hline \hline
\end{tabular}

When we consider the dynamics, then the environmental parameters $\delta, b$ and $K$ also play a role as shown in the law of motion in Equation (5). Assuming that one period lasts for 20 years, the intrinsic regeneration growth rate $\delta$ can be set at 0.08 (in accord with Matsumoto (2002) and Dalton and Coats (2000) that suggest a $4 \%$ growth rate per decade). Using the same assumptions as Matsumoto, the coefficient for the human impact on resources $b$ turns out to have the order of magnitude of $10^{-4}$ on our scale. The carrying capacity $K$, which acts as a scaling parameter, is set at 12000 as elsewhere in the literature. ${ }^{22}$

\footnotetext{
${ }^{22}$ See Matsumoto (2002), Brander and Taylor (1998), Pezzey and Anderies (2003), Erickson and Gowdy (2000), Dalton and Coats (2000), Flenley et al. (1991). The meaning of the parameters will be discussed in more detail in Section 5, with respect to the cases of Tikopia and Easter Island.
} 
Here we will focus on the parameters $\mu$ and $\omega$ in two cases. In Case I they take the same values as in Section 3.2: $\{\omega=0 ; \mu=1\}$, so that Case I is a numerical example satisfying Assumption 1. Case II is characterized by a larger value for both parameters: $\{\omega=0.1 ; \mu=1.3\}$. For both cases we consider the fertility choice problem at given $t .{ }^{23}$ The resulting equilibrium fertility choices and bargained share are shown in Table 2 . In both cases optimal fertility is higher for Group 1 than for Group 2 because its size is initially lower. Moreover, in Case II, there is a higher equilibrium level of fertility for both groups. This arises because the probability of success in war is more sensitive to the groups' relative sizes, giving a stronger incentive to have children. This is also reflected in the fact that, for given population size, Group 1's share $\left(\theta_{t}\right)$ is smaller in Case II than in Case I. Figure 4 shows the reaction functions. The positive slope which was demonstrated analytically in the neighborhood of the equilibrium for Assumption 1 holds also when the values of $\mu$ and $\omega$ are somewhat different.

Table 2: Outcome for generation born at $t$, Cases I and II

\begin{tabular}{l|cccc}
\hline \hline Case & $n_{1, t}$ & $n_{2, t}$ & $\theta_{t}$ & $\theta_{t+1}$ \\
\hline I & 1.036 & 0.965 & .474 & .491 \\
II & 1.465 & 1.356 & .469 & .492 \\
\hline \hline
\end{tabular}

Figure 4: Fertility reaction functions: Case I (solid); Case II (dashed)

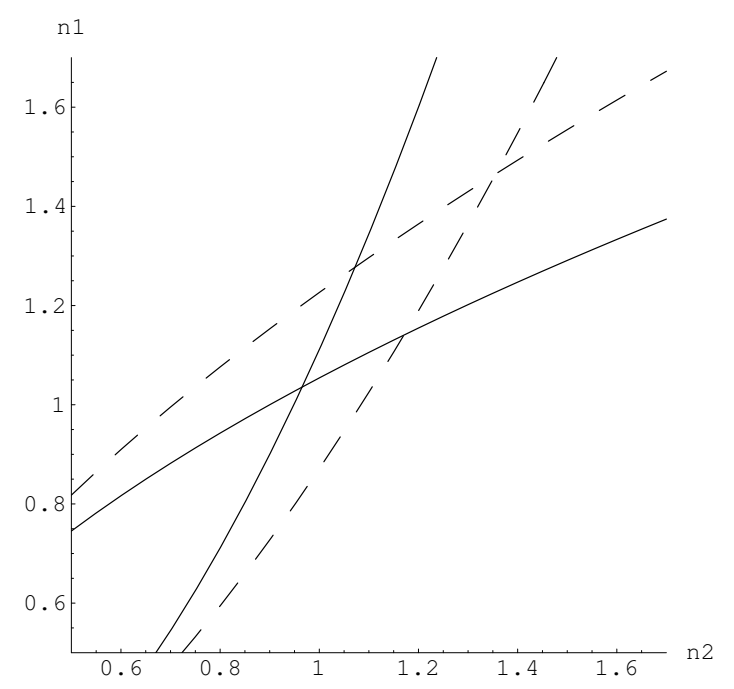

\footnotetext{
${ }^{23}$ Notice that in the fertility problem $R_{t+1}$ is exogenous. Moreover given that $\lambda=0$, the resource stock is just a multiplicative term that does not affect the fertility choice.
} 


\subsection{Concave Utility}

Let us now remove the assumption of a linear utility function. The function becomes CRRA (Constant Relative Risk Aversion): $\left(c_{i, t}^{1-\sigma}+\beta d_{i, t+1}^{1-\sigma}\right) /(1-\sigma)-\lambda n_{i, t}$ where $\sigma \geq 0$ is the parameter capturing the degree of relative risk aversion. ${ }^{24}$ Notice that the solution to the bargaining problem still does not depend on second period consumption (since it is unaffected by current bargaining) or on the disutility of child rearing (as fertility is chosen before the clans begin their bargaining). However the solution to the bargaining problem is no longer given by Equation (8), because risk aversion has been introduced. Clans still have foresight over $\theta_{t+1}$, internalizing the fact that it depends on their relative size, but the way in which $\theta_{t+1}$ responds to current fertility is different from the response without risk aversion.

We can now study the effect of an increase in risk aversion $\sigma$ on $\theta$ which results from bargaining in a neighborhood of the analytically treatable solution. This allows us to study the conditions under which increasing risk aversion implies a greater share for Group 1 than in the linear case (i.e. when $\sigma=0$ ). Abstracting from constant terms, and omitting for simplicity the temporal subscript for $\pi$ and $\theta$, the maximization of the Nash product (7) yields the first order condition

$$
\frac{1-\gamma}{(1-\pi)(1-\omega)(1-\theta)^{\sigma}-(1-\theta)(1-\omega)^{\sigma}}=\frac{\gamma}{\pi \theta^{\sigma}(1-\omega)-\theta(1-\omega)^{\sigma}}
$$

By applying the implicit function theorem it is possible to derive an expression for $\frac{d \theta}{d \sigma}$. Although such an expression is not easy to handle, we can study the situation in the neighborhood of $\sigma=0$ as our aim is to study the effect of introducing risk aversion into the expression. As in Section 3.2 we focus on the neighborhood of $\omega=0$, obtaining:

$$
\frac{d \theta}{d \sigma}=\pi(1-\gamma) \ln (\pi)-\gamma(1-\pi) \ln (1-\pi)
$$

Rearranging this expression gives

$$
\frac{d \theta}{d \sigma} \geq 0 \quad \Leftrightarrow \quad \frac{(1-\pi) \ln (1-\pi)}{\pi \ln (\pi)} \geq \frac{1-\gamma}{\gamma}
$$

Since the l.h.s. of this inequality turns out to be unambiguously increasing in $\pi$ as $\pi \in(0,1)$, it is clear that the effect of introducing risk aversion is more likely to increase Group 1's share if, for a given population size (and hence $\pi$ ), $\gamma$ is high enough, or, for a given $\gamma, \pi$ is high enough. The rationale behind these results is that when risk aversion is introduced, the clan with greater contractual force $(\gamma$ and $1-\gamma)$ and military power

\footnotetext{
${ }^{24}$ We assume that both clans are risk averse to the same extent. If the parties differ in their degree of risk aversion, the bargaining position of the less risk averse party is improved (Binmore, Rubinstein, and Wolinsky 1986). It would be possible to relax the assumption of the linear disutility of children as well, but the qualitative results would not change. What would occur is that, ceteris paribus, introducing decreasing returns in child disutility would increase fertility.
} 
$(\pi$ and $1-\pi)$ benefits. This occurs because groups are more anxious to avoid the risky outcomes associated with a lack of agreement, and hence the most powerful group has an advantage. In particular, this means that, for a given exogenous contractual force, the bargained share becomes more sensitive to relative population, since this affects the groups' military power. This means that the strategic motive is enhanced when risk aversion is introduced into the model.

Numerical simulations are needed to obtain results for the fertility choice as risk aversion increases further. ${ }^{25}$ The results of such simulations on fertility rates and bargained share as risk aversion increases for Cases I and II are shown in Table 3. We can see how, for a given risk aversion, fertility rates are always greater in Case II, because the relative size is more decisive in this case. As expected, greater risk aversion initially brings about higher fertility rates. However such an effect is not monotonic: when $\sigma$ is close to 1 fertility rates begin to decrease. This down-turn occurs because, if $\sigma$ is high enough, $\theta$ is less affected by the groups' relative size (see $\theta_{t}$ rows) and the strategic motive becomes weaker and weaker. Notice however that, in both cases, for utility function approaching the logarithmic form (i.e. $\sigma \rightarrow 1$ ) we do not observe less fertility than in the benchmark model with risk neutrality. Therefore the basic model seems to be robust to introduction of risk aversion.

Table 3: Fertility rates and bargained shares for different levels of risk aversion

\begin{tabular}{l|rrrrrr}
\hline \hline & $\sigma=0$ & $\sigma=.1$ & $\sigma=.2$ & $\sigma=.5$ & $\sigma \rightarrow 1$ & $\sigma=2$ \\
\hline Case I & & & & & & \\
$n_{1, t}$ & 1.036 & 1.065 & 1.096 & 1.253 & 1.036 & 0.340 \\
$n_{2, t}$ & 0.965 & 0.993 & 1.020 & 1.163 & 0.965 & 0.326 \\
$\theta_{t}$ & .474 & .473 & .472 & .471 & .474 & .487 \\
$\theta_{t+1}$ & .491 & .491 & .492 & .491 & .491 & .492 \\
Case II & & & & & & \\
$n_{1, t}$ & 1.465 & 1.500 & 1.545 & 1.989 & 1.936 & 0.706 \\
$n_{2, t}$ & 1.356 & 1.387 & 1.428 & 1.830 & 1.782 & 0.664 \\
$\theta_{t}$ & .469 & .468 & .468 & .465 & .466 & .478 \\
$\theta_{t+1}$ & .492 & .492 & .492 & .493 & .493 & .491 \\
\hline \hline
\end{tabular}

\subsection{Resources and Population Dynamics}

In Section 3.4 we studied the dynamics of the particular configuration which allows analytical solutions. Here we will use numerical simulations to extend the analysis to the general model, so as to see which factors make the occurrence of a collapse more

\footnotetext{
${ }^{25}$ We cannot compute a closed form solution $\theta_{t}$ as a function of $n_{1, t}$ and $n_{2, t}$ and hence the second step (the choice of fertility) cannot be solved explicitly, even under Assumption 1.
} 
likely. The aim is to discover under which configuration of parameters the dynamics converge to a steady state.

Non-convergence can reflect two different situations. The first - which we label 'population collapse'- arises when the population converges asymptotically to zero while resources achieve their carrying capacity $K$. This represents a world where fertility is below replacement level in the long-run. The second situation - labeled 'environmental collapse' - arises when resources are exhausted following a population boom. This also causes the extinction of the population, as no crops are produced. Contrary to the 'population collapse' case, the 'environmental collapse' leads to the extinction of population in finite time.

For the benchmark parametrization we focus on the role of the parameters $\omega$ and $\mu$, which have not been considered so far in the literature. The meaning of these parameters will be discussed more extensively in Section 5, as will the historical evidence for differences between Easter and Tikopia Islands. The parameters for the benchmark specification are as shown in Table 1 but for $\lambda$ which is set to 1 . If $\lambda=0$ fertility does not depend on resources and on actual clans' populations but just on their ratio: if this is the case, then fertility remains generally different from 1 (except in the case of Assumption 1 - Proposition 3), leading either to population collapse or to environmental collapse. Instead with a strictly positive $\lambda$, fertility is related to the actual stock of resources and populations and a there exists a range of parameters $\mu$ and $\omega$ such that collapse can be avoided. The setting $\lambda=1$ is chosen for the sake of simplicity. The values for $N_{1, t}$ and $N_{2, t}$ are used as initial values, and the value for $K$ is taken as the initial value for $R_{t}$. Figure 5 shows the three regions in the $\{\mu ; \omega\}$ space separated by bold curves.

The top-left region represents the zone of population collapse, the central area is the no-collapse zone where a long run stable equilibrium of population and resources can be reached, and the bottom right represents environmental collapse. We can see that the frontiers all have positive slopes: a collapse is avoided if neither of these two parameters is 'too large' compared to the other. In particular, an environmental collapse becomes more likely if, for a given $\omega, \mu$ is high, or if for a given $\mu, \omega$ is low.

By performing a ceteris paribus perturbation of the parameters we can assess the effects of other model parameters on the collapse zones. ${ }^{26}$ Figure 5 shows how the borderlines move as the parameters change. Both borderlines are affected by every parameter, but the effect on the left frontier is so small in some cases that we do not report it systematically. This shows that:

- a drop in the disutility of children $\lambda$ reduces the stable population zone and increases the environmental collapse zone;

- higher old age transfers $\tau$ enlarge the zone of environmental collapse and shrink the zone of no-collapse;

\footnotetext{
${ }^{26}$ All the simulations are available from the authors upon request.
} 
Figure 5: Collapse zones as a function of parameters

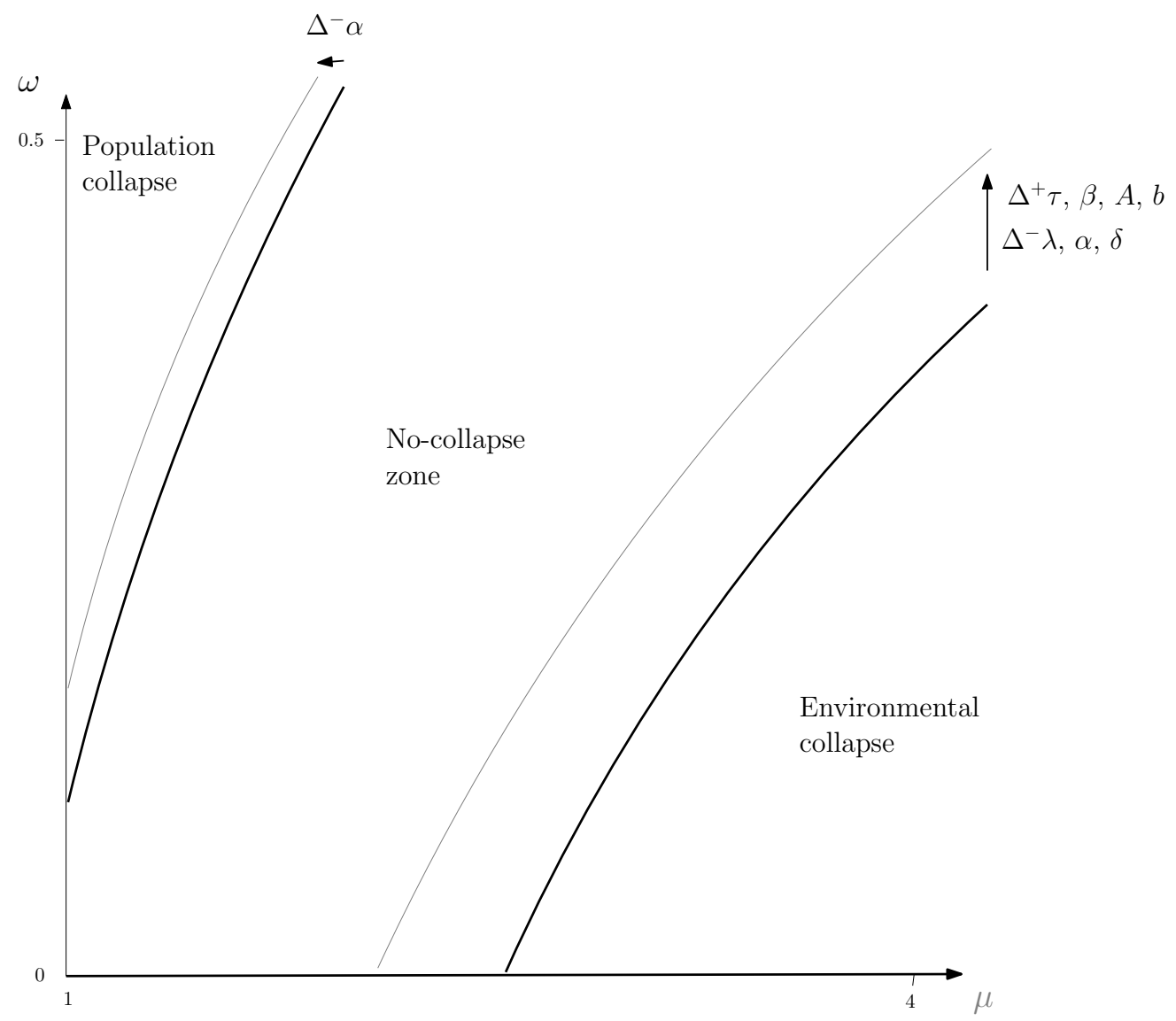

- less severe decreasing returns to labor $\left(\Delta^{-} \alpha\right)$ reduce the scope for population collapse, enlarge the zone of environmental collapse, and move the zone of nocollapse;

- lower discounting with time (higher $\beta$ ) enlarges the zone of environmental collapse and reduces the zone of no-collapse;

- higher productivity $A$ reduces the stability zone and enlarges the zone of environmental collapse.

- lower $\delta$ or higher $b$, both implying a more fragile ecosystem, reduces the zone of no-collapse and enlarges the zone of environmental collapse.

Basically, the parameters which have been proved in Corollary 1 and 2 to have a positive impact on fertility enlarges the scope for environmental collapse by increasing the pressure on resources. 
Additional non-reported simulations show that, when exogenous asymmetries are very important ( $\gamma$ close to 0 or to 1 and $\omega$ high), the population collapse zone is enlarged and the environmental collapse zone is reduced. With large exogenous asymmetries, the strategic incentive to compete on size is weaker. The weaker group knows that it is not worth increasing fertility for strategic reasons.

\section{Discussion}

In this model, fertility is not determined through mechanistic Malthusian dynamics but is the outcome of a rational choice by decision makers, with a finite life-span, who are aware of some trade-off in choosing how many children to raise. In particular one of the motives related to fertility choice has a strategic nature, since it is related to bargaining over crop sharing in the next period.

A new way to look at fertility is proposed, suggesting that strategic complementarities can characterize fertility behavior across groups. When the relative size provides advantages, as in this model in relation to military power, each group's fertility decision is affected by expectations about the other group's decision. We studied under what conditions this can result in over-population. Up to now the number of children has usually been studied either as automatically determined by nutrition (in a Malthusian fashion), as a consumption good (assuming altruistic motives), or as an investment good (for old age support). Our framework has elements of all these traditions, but differs substantially from them since the relative size also matters, thus determining fertility complementarity.

Moreover, groups are neither completely myopic, nor very-long-term optimizers. It is assumed that they were not interested in the impact of their fertility behavior in the very long run, but also that they cared about the effects of their actions for at least the whole of their lifetime. The assumption of perfect foresight is the simplest way to model agents who are aware that their consumption tomorrow will be affected by their groups' relative size and thus by their fertility decision today.

Furthermore, the model adds new factors (e.g. $\omega, \mu$ ) that play a role influencing human decisions to the elements already considered in the literature on fragile ecosystems $(\delta$, $b)$. Even if two societies are similar with respect to the second group of parameters they may experience very different patterns if they differ substantially with respect to the first group. Though simple, the model highlights how these factors can affect fertility decisions when crop sharing is decided by bargaining. It is worth remarking that fertility reaction functions with positive slopes is a necessary but not sufficient condition for a population race to occur. In order for a population race to happen the strategic complementarity must force fertility high enough. This turns out to depend also on parameters related to geography and climate. 
Previous economic literature has stressed the climatic differences between Easter and Tikopia Islands. Easter Island is located at a latitude of $27^{\circ}$ South, while Tikopia's latitude is $12.29^{\circ}$ South: this determines a first important difference since the climate is colder on Easter Island. Moreover while Tikopia has relatively high rainfall, with an annual dry season in May-June, Easter Island exhibits drier weather. Rolett and Diamond (2004) find that both cold and dryness are important in determining the likelihood of deforestation in a sample of small Pacific Islands. Other important factors are the exposure to aerial volcanic fallout and Asian dust plumes, and the presence of a rock called makatea. Tikopia is ranked much higher than Easter Island on these factors. Applying all this evidence to the model suggests that the intrinsic resource growth rate $\delta$ was lower for Easter Island. ${ }^{27}$ Dalton and Coats (2000) remark that the indigenous palm has a very low inherent growth rate due to the southern latitude of the island, the amount of annual rainfall, and the quality of the soil (see Ladefoged et al. (2005)). As Equation (14) shows, a lower $\delta$ increases the likelihood of an environmental trap that determines the collapse of a society. Moreover the remoteness of Easter Island ${ }^{28}$ might have spurred the deforestation by increasing the opportunity for doing things which have an impact on the environment (as suggested by Diamond 2005, p. 108). This can be seen in a higher $b$, the coefficient of human impact on resource growth, for Easter Island, which ceteris paribus makes it easier for the environmental trap to occur.

The role that differences in parameters such as $b$ and $\delta$ have played in favoring the Tikopian ecosystem has already been considered by Erickson and Gowdy (2000). But there are also geographical features against Tikopia. For example the smaller area of Tikopia $^{29}$ means that the perimeter/area ratio is larger, and the initial percentage of forest area is smaller. Moreover Tikopia was subject to periodic cyclones (approximately 20 per decade) which prevented almost all human activity and compelled the inhabitants to stockpile food in advance. Diamond (2005) reports that "fields in Tikopia require almost constant labor input for weeding, plus mulching with grass and brushwood to prevent crop plants from drying out." However in Easter Island the "upland plantation did not require year-round effort: the peasants just had to march up and plant taro and other root crops in the spring then return later in the year for the harvest" (Diamond 2005, p. 93). All this can be interpreted as a higher value of $\omega$ in the Tikopian economy: $\omega$ really captures the cost of waging war, in terms of missed/wasted/not-enjoyed crop consumption. When agents have less time available, and they have to use part of this time in stockpiling resources, devoting their time to fighting is likely to involve a greater cost. Our model suggests that a greater $\omega$ reduces fertility, so that even if being bigger provides greater military power, this is unlikely to trigger a population race.

\footnotetext{
${ }^{27} \mathrm{~A}$ lower $\delta$ could also be caused by a higher presence of rats on Easter Island which ate palm fruits and prevented regeneration (Flenley and Bahn 2003).

${ }^{28}$ Easter Island is more than $3200 \mathrm{~km}$ west of the nearest continent (South America) and $2250 \mathrm{~km}$ from the nearest populated island (Pitcairn). Tikopia's closest island is $136.8 \mathrm{~km}$ away, while the closest large island is $225 \mathrm{~km}$ away.

${ }^{29}$ Tikopia covers $5 \mathrm{~km}^{2}$ whereas Easter Island's area is $166 \mathrm{~km}^{2}$.
} 
The parameter $\mu$ also plays an important role in our model. Such a parameter is inherent to warfare and captures the sensitivity of the probability of success in war to relative numbers of fighters. We have seen that, with a high sensitivity, a population race can be triggered. Münster and Staal (2005) suggest that such a parameter should be considered as determined both by technological factors (for example, war technology) and institutional factors (social security and cohesion). It is reasonable to believe that war technology at the time we are interested in was very labor intensive, so that differences in the number of fighters could play a substantial role. On the other hand we have no clear evidence that the clans differed very much with respect to war technology or weapons. However Hirshleifer (1995) claims that a low $\mu$ "in military struggles [...] corresponds to the defense having the upper hand"(p. 32). ${ }^{30}$ Possible advantages for the defensive position, with respect to the attacking one, can depend on features of the terrain. Easter Island's topography is mostly gentle without the deep valleys which are common elsewhere in the Pacific Islands. ${ }^{31}$ Moreover the makatea terrain - which is present on Tikopia but not on Easter Island - is extremely difficult to walk over as it is razor-sharp and cutting. Such terrain is likely favor defenders rather than attackers in a fight, and can so be interpreted as evidence for a lower $\mu$ on Tikopia.

Hirshleifer (1995) suggests several historical examples where the decisiveness of conflict is compatible with the establishment of a hierarchical society, whereas when $\mu$ is small a less stratified society without strong hierarchies can be sustainable. All that is consistent with the differences between Easter Island and Tikopian societies: Easter Island was characterized by a highly hierarchic structure whereas Tikopia was one of the least stratified societies in Polynesia. We do not claim that the institutional setting was the determinant of $\mu$ (as Münster and Staal (2005) do); on the contrary, it is possible that the institutional setting has been the outcome of the differential decisiveness of conflict. At the very least, what occurred historically is consistent with a higher value of $\mu$ for Easter Island.

\section{Conclusion}

In this paper we suggested that a population race that could help to explain the different patterns experienced in the past by two small societies in the Pacific Ocean: Easter Island where the population grew considerably over time and then decreased sharply, and Tikopia where the population remained roughly steady over centuries. In the absence of strong property rights, income distribution is governed by bargaining between clans. Bargaining power is influenced by the threat of waging war. Since the probability of

\footnotetext{
${ }^{30}$ This view is not shared by Grossman and Kim (1995) who model disparities between attack and defense through another parameter.

31 "Except at the step sided craters and cinder crones, [it is] possible almost anywhere in Easter to walk safely in a straight line to anywhere else nearby." (Diamond 2005, p. 83). Easter Island's gentle terrain may also help to explain why it was much more integrated than the Marquesas Islands, where people living in adjacent valleys communicated each other mainly by sea rather than overland.
} 
winning a war is positively affected by the number of fighters available, relative size matters: a bigger clan is more powerful and can achieve a greater share of the crop.

The resulting strategic interaction among clans can result in over-population, rapid depletion of renewable resources, and ultimately the collapse of the whole society. We discussed factors making the occurrence of a collapse more likely, using historical and archaeological evidence to assess possible differences in them between Easter Island and Tikopia. On top of the factors already highlighted in the literature, we considered the role played by the cost of conflict $(\omega)$, and the decisiveness of having more people in determining the outcome of a war $(\mu)$. Without neglecting the role of other elements, we suggest that these factors, through their influence on human behavior, may also have played an important role in the intensity of a population race and the path to collapse. In particular, the agriculture type and the presence of cyclones makes war more costly in Tikopia, deterring clans to compete in size to gain military power.

One interesting feature of our approach, compared to that elsewhere in the literature, is that the assumption of a mechanistic dynamics for population is relaxed. It is often assumed that, in the least developed societies, fertility simply follows Malthusian dynamics. However the different demographic patterns followed by similar non-developed societies, plus evidence of an awareness of fertility behavior (supported by historical indications of fertility as a social norm) suggest that a deeper analysis of fertility may be profitable. In our model fertility turns out to be a utility-maximizing choice, whose micro-determinants can be investigated.

The commonly made assumption of highly myopic behavior is also relaxed by introducing foresight and inter-temporal choice (as recommended by Reuveny and Maxwell (2001)). This does not mean that decision makers are aware of long-run resource dynamics, but simply that they are aware that they have to take decisions which will affect them during the whole of their lifetime: perhaps the clearest example of this is the decision about how many children to rear.

Another contribution of this paper is that it provides a new way of looking at fertility, since it features strategic complementarity between groups' sizes. The mechanism through which being larger yields an advantage provides a further motive for fertility choices, in addition to those generally highlighted (old age support, family altruism, etc.). In our model this motive can be traced back to the absence of property rights over output, but the principle can easily be extended to any situation where the relative size of a group influences its expected payoffs. Consider, for instance, tensions between two groups where one feels much weaker in war or weapon technology: enlarging its population can be seen as a means to increase its power and partly bridge the gap. In a bargaining situations the bigger group can take advantage of its size by making its voice louder (for example, in subsidy seeking); or in contexts where creating a relative 
advantage through size can be seen as means of defense and evaluated positively. ${ }^{32}$

Easter Island is often cited as an example of how a closed system can collapse in an endogenous way. Although the focus of this paper is on an episode of the past, it can be also seen as a metaphor for the management of resources within a society. If important features of modern development (technological progress, international trade) are disregarded, the model highlights the dangers involved in a race for a positional rent. In this respect the population race can become an arms race, reminiscent of episodes in the Cold War as well as more recent international tensions.

\section{References}

Anderies, J. M. 2000. "On modeling human behavior and institutions in simple ecological economic systems." Ecological Economics 35:393-412.

Basener, B., and D.S. Ross. 2005. "Booming and Crashing Populations and Easter Island." SIAM Journal of Applied Math 65 (2): 684-701.

Binmore, K, A. Rubinstein, and A. Wolinsky. 1986. "The Nash bargaining solution in economic modelling." Rand Journal of Economics 17 (2): 176-188.

Brander, J.A., and M.S. Taylor. 1998. "The Simple Economics of Easter Island: A Ricardo-Malthus Model of Renewable Resource Use." American Economic Review 88 (1): 119-138 (March).

Cohen, J. 1995. How Many People Can the Earth Support. W. W. Norton and Company.

Dalton, T.R., R.M. Coase, and R.A. Badiollah. 2005. "Renewable resources, propertyrights regimes and endogenous growth." Ecological Economics 52:31-41.

Dalton, T.R., and R. M. Coats. 2000. "Could institutional reform have saved Easter Island?" Journal of Evolutionary Economics 10:489-505.

Diamond, J. 2005. Collapse. How societies choose to fail or survive. Viking Books.

Ehrlich, I., and F. T. Lui. 1991. "Intergenerational Trade, Longevity, and Economic Growth." Journal of Political Economy 99 (5): 1029-59 (October).

Erickson, J.D., and J. M. Gowdy. 2000. "Resource Use, Institutions, and Sustainability: a Tale of Two Pacific Island Cultures." Land Economics 76 (3): 345-354 (August).

Flenley, J., and P. Bahn. 2003. The enigmas of Easter Island. Oxford University Press.

Flenley, J, A King, J Teller, M Prentice, J Jackson, and C Chew. 1991. "The Late Quaternary vegetational and climatix history of Easter Island." Journal of Quaternary Science 6 (2): 85-115.

\footnotetext{
${ }^{32} \mathrm{An}$ example of a population race for strategic motives, is, according to many, the episode of la revanche des berceaux (the revenge of the cradles) when Quebec's population more than doubled in 40 years in the mid XIXth century.
} 
Grossman, Herschel I, and Minseong Kim. 1995. "Swords or Plowshares? A Theory of the Security of Claims to Property." Journal of Political Economy 103 (6): 1275-88 (December).

Hahn, F.H. 1962. "The Stability of the Cournot Oligopoly Solution." Review of Economic Studies 29 (4): 329-331 (October).

Harford, J.D. 2000. "Methods of pricing common property use and some implications for optimal child-bearing and the social discount rate." Resource and Energy Economics 22:103-124.

Hirshleifer, J. 1991. "The technology of conflict as an economic activity." American Economic Review 81 (2): 130-134.

- 1995. "Anarchy and its Breakdown." Journal of Political Economy 103 (1): $26-52$.

Keegan, J. 1993. A history of warfare. New York: Knopf.

Kirch, Patrick V. 1986. "Exchange systems and inter-island contact in the transformation of an island society." In Island Socities: Archaeological Approaches to Evolution and Tranformation. Cambridge University Press.

Kirch, Patrick V., and D. Yen. 1982. "Tikopia: The Prehistory and Ecology of a Polynesia Outlier." Bishop Museum Bulletin. Honolulu.

Ladefoged, T., C. Stevenson, P. Vitousek, and O. Chadwick. 2005. "Soil Nutrient Depletion and the Collapse of Rapa Nui Society." Rapa Nui Journal 19 (2): 100105 (October).

Lagerloef, Nils-Petter. 2006. "The Galor-Weil Model Revisited: A Quantitative Exercise." Review of Economic Dynamics 9:116-142.

Lasserre, P., and A. Souberyan. 2003. "A Ricardian model of the tragedy of the commons." Journal of Economic Behavior and Organization 50:29-45.

Matsumoto, A. 2002. "Economic Dynamic Model for Small Islands." Discrete Dynamics in Nature and Society 7 (2): 121-132.

Maxwell, W., and R. Reuveny. 2005. "Continuing conflict." Journal of Economic Behavior and Organization 58:30-52.

Münster, Johannes, and Klaas Staal. 2005, December. "War with Outsiders Makes Peace Inside." Discussion papers 75, SFB/TR 15 Governance and the Efficiency of Economic Systems.

Owsley, D.W., G.W. Will, and S.D. Ousley. 1994. "Biological Effects of European Contacts on Easter Island." Edited by C. M. Stevenson, G. Lee, and F.J. Morin, Easter Island in Pacific Context: South Seas Symposium: Proceedings of the Fourth International Conference on Easter Island and East Polynesia. Easter Island Foundation, 129-34. 
Pezzey, J.C.V., and J.M. Anderies. 2003. "The effect of subsistence on collapse and institutional adaptation in population-resource societies." Journal of Development Economics 72:299-320.

Ponting, C. 1991. A green history of the world: the environment and the collapse of great civilizations. New York: Penguin.

Prskawetz, A., A. Gragnani, and G. Feichtinger. 2003. "Reconsidering the Dynamic Interaction of Renewable Resources and Population Growth: a focus on long run sustainability." Environmental Modeling \& Assessment 8:35-45.

Rainbird, P. 2002. "A Message for our Future? The Rapa Nui (Easter Island) Ecodisaster and Pacific Islands Environment." World Archaelogy 33 (3): 436-51 (February).

Reuveny, R., and C.S. Decker. 2000. "Easter Island: historical anecdote or warning for the future?" Ecological Economics 35:271-287.

Reuveny, R., and W. Maxwell. 2001. "Conflict and Renewable Resource." The Journal of Conflict Resolution 45 (6): 719-742 (Dec).

Rolett, B., and J. Diamond. 2004. "Environmental predictors of pre-European deforestation on Pacific islands." Nature 431 (Issue 7007): 443-446.

Skaperdas, S. 1996. "Contest success functions." Economic Theory 7 (2): 283-90.

\section{A Appendix}

\section{A.1 Proof of Corollary 1}

Total differentiation of Equations (9) and (10) at the Nash equilibrium under Assumption 1 yields:

$$
\begin{gathered}
-\frac{2 N_{1, t}^{2 / 3}}{\left(N_{1, t}^{1 / 3}+N_{2, t}^{1 / 3}\right)^{4} N_{2, t}^{1 / 3}} d n_{1, t}+\frac{N_{2, t}^{1 / 3}}{\left(N_{1, t}^{1 / 3}+N_{2, t}^{1 / 3}\right)^{4}} d n_{2, t}-\frac{\gamma}{N_{1, t}^{1 / 3}\left(N_{1, t}^{1 / 3}+N_{2, t}^{1 / 3}\right)^{2}} d \omega+ \\
+\frac{N_{1, t}^{1 / 3}+N_{2, t}^{1 / 3}+\frac{1}{3} N_{1, t}^{1 / 3} \ln \left(\frac{N_{2, t}}{N_{1, t}}\right)}{\left(N_{1, t}^{1 / 3}+N_{2, t}^{1 / 3}\right)^{4}} d \mu-\frac{\left(\frac{N_{1, t}}{N_{2, t}}\right)^{1 / 3}}{\left(N_{1, t}^{1 / 3}+N_{2, t}^{1 / 3}\right)^{3}} d \alpha-\frac{1}{A_{t+1} \beta \tau} d \lambda=0
\end{gathered}
$$

and

$$
\begin{aligned}
\frac{N_{1, t}^{1 / 3}}{\left(N_{1, t}^{1 / 3}+N_{2, t}^{1 / 3}\right)^{4}} d n_{1, t}-\frac{2 N_{2, t}^{2 / 3}}{N_{1, t}^{1 / 3}\left(N_{1, t}^{1 / 3}+N_{2, t}^{1 / 3}\right)^{4}} d n_{2, t}-\frac{1-\gamma}{N_{2, t}^{1 / 3}\left(N_{1, t}^{1 / 3}+N_{2, t}^{1 / 3}\right)^{2}} d \omega+ \\
\frac{N_{1, t}^{1 / 3}+N_{2, t}^{1 / 3}+\frac{1}{3} N_{2, t}^{1 / 3} \ln \left(\frac{N_{1, t}}{N_{2, t}}\right)}{\left(N_{1, t}^{1 / 3}+N_{2, t}^{1 / 3}\right)^{4}} d \mu-\frac{\left(\frac{N_{2, t}}{N_{1, t}}\right)^{1 / 3}}{\left(N_{1, t}^{1 / 3}+N_{2, t}^{1 / 3}\right)^{3}} d \alpha-\frac{1}{A_{t+1} \beta \tau} d \lambda=0 .
\end{aligned}
$$


These expressions can be written in matrix form as:

$$
\begin{aligned}
& \left(\begin{array}{cc}
1 & -\frac{1}{2}\left(\frac{N_{2, t}}{N_{1, t}}\right)^{2 / 3} \\
-\frac{1}{2}\left(\frac{N_{1, t}}{N_{2, t}}\right)^{2 / 3} & 1
\end{array}\right)\left[\begin{array}{l}
d n_{1, t} \\
d n_{2, t}
\end{array}\right]= \\
& \left(\begin{array}{cc}
\frac{N_{2, t}^{1 / 3}}{2 N_{1, t}}\left[\left(\frac{N_{2, t}}{N_{1, t}}\right)^{1 / 3}+1+\frac{1}{3} \ln \left(\frac{N_{2, t}}{N_{1, t}}\right)\right] & -\gamma \frac{\left(N_{1, t}^{1 / 3}+N_{2, t}^{1 / 3}\right)^{2} N_{2, t}^{1 / 3}}{2 N_{1, t}} \\
\frac{N_{1, t}^{1 / 3}}{2 N_{2, t}}\left[\left(\frac{N_{1, t}}{N_{2, t}}\right)^{1 / 3}+1+\frac{1}{3} \ln \left(\frac{N_{1, t}}{N_{2, t}}\right)\right] & -(1-\gamma) \frac{\left(N_{1, t}^{1 / 3}+N_{2, t}^{1 / 3}\right)^{2} N_{1, t}^{1 / 3}}{2 N_{2, t}}
\end{array}\right. \\
& \left.\begin{array}{ll}
-\frac{\left(N_{1, t}^{1 / 3}+N_{2, t}^{1 / 3}\right)^{4} N_{2, t}^{1 / 3}}{2 A_{t+1} N_{1, t}^{2 / 3} \beta \tau} & -\frac{1}{2}\left[1+\left(\frac{N_{2, t}}{N_{1, t}}\right)^{1 / 3}\right] \\
-\frac{\left(N_{1, t}^{1 / 3}+N_{2, t}^{1 / 3}\right)^{4} N_{1, t}^{1 / 3}}{2 A_{t+1} N_{2, t}^{2 / 3} \beta \tau} & -\frac{1}{2}\left[1+\left(\frac{N_{1, t}}{N_{2, t}}\right)^{1 / 3}\right]
\end{array}\right]\left[\begin{array}{c}
d \mu \\
d \omega \\
d \lambda \\
d \alpha
\end{array}\right] .
\end{aligned}
$$

The left coefficient matrix is positive definite and can be inverted to give

$$
\left(\begin{array}{cc}
\frac{4}{3} & \frac{2}{3}\left(\frac{N_{2, t}}{N_{1, t}}\right)^{2 / 3} \\
\frac{2}{3}\left(\frac{N_{1, t}}{N_{2, t}}\right)^{2 / 3} & \frac{4}{3}
\end{array}\right) .
$$

Pre-multiplying both sides of Equation (16) by this matrix gives:

$$
\begin{array}{r}
{\left[\begin{array}{l}
d n_{1, t} \\
d n_{2, t}
\end{array}\right]=\left(\begin{array}{cc}
\frac{1}{3}+\left(\frac{N_{2, t}}{N_{1, t}}\right)^{\frac{1}{3}}\left[1+\frac{1}{9} \ln \left(\frac{N_{2, t}}{N_{1, t}}\right)\right]+\frac{2}{3}\left(\frac{N_{2, t}}{N_{1, t}}\right)^{\frac{2}{3}} & -\frac{\left(N_{1, t}^{\frac{1}{3}}+N_{2, t}^{\frac{1}{3}}\right)^{2}\left[(1-\gamma)\left(N_{1, t}^{2} N_{2, t}\right)^{\frac{1}{3}}+2 \gamma N_{2, t}\right]}{3 N_{1, t} N_{2, t}^{\frac{2}{3}}} \\
\frac{1}{3}+\left(\frac{N_{1, t}}{N_{2, t}}\right)^{\frac{1}{3}}\left[1+\frac{1}{9} \ln \left(\frac{N_{1, t}}{N_{2, t}}\right)\right]+\frac{2}{3}\left(\frac{N_{1, t}}{N_{2, t}}\right)^{\frac{2}{3}} & -\frac{\left(N_{1, t}^{\frac{1}{3}}+N_{2, t}^{\frac{1}{3}}\right)^{2}\left[(1-\gamma) 2 N_{1, t}+\gamma\left(N_{1, t} N_{2, t}^{2}\right)^{\frac{1}{3}}\right]}{3 N_{1, t}^{\frac{2}{3}} N_{2, t}} \\
-\frac{\left(N_{1, t}^{1 / 3}+N_{2, t}^{1 / 3}\right)^{4}\left(N_{1, t}^{1 / 3}+2 N_{2, t}^{1 / 3}\right)}{3 A_{t+1} N_{1, t}^{2 / 3} \beta \tau} & -\frac{1}{3}\left[1+\left(\frac{N_{2, t}}{N_{1, t}}\right)^{1 / 3}\right]\left[2+\left(\frac{N_{2, t}}{N_{1, t}}\right)^{1 / 3}\right] \\
d \mu \\
-\frac{\left(N_{1, t}^{1 / 3}+N_{2, t}^{1 / 3}\right)^{4}\left(2 N_{1, t}^{1 / 3}+N_{2, t}^{1 / 3}\right)}{3 A_{t+1} N_{2, t}^{2 / 3} \beta \tau} & -\frac{1}{3}\left[1+\left(\frac{N_{1, t}}{N_{2, t}}\right)^{1 / 3}\right]\left[2+\left(\frac{N_{1, t}}{N_{2, t}}\right)^{1 / 3}\right]
\end{array}\right]\left[\begin{array}{c}
d \omega \\
d \lambda] \cdot(17) \\
d \alpha
\end{array}\right]}
\end{array}
$$

The effects are all unambiguous: the effects of $\omega, \lambda$, and $\alpha$ are negative whereas the effect of $\mu$ is positive. 


\section{A.2 Proof of Corollary 2}

Let us denote Equations (9) and (10) by $\Phi$ and $\Psi$ respectively. If we differentiate with respect to $\beta$ and $\tau$ we obtain the following equations whose sign is unambiguous:

$$
\begin{aligned}
& \frac{\partial \Phi}{\partial \beta}=\frac{\partial \Psi}{\partial \beta}=\frac{\lambda}{\beta^{2} \tau} \\
& \frac{\partial \Psi}{\partial \tau}=\frac{\partial \Psi}{\partial \tau}=\frac{\lambda}{\beta \tau^{2}} .
\end{aligned}
$$

When the reaction functions both have positive slopes the effect of a change in parameters on the equilibrium fertility can be assessed by looking directly at the shift in $\Phi$ and $\Psi$.

When $\gamma$ is involved we obtain an unambiguous effect if we keep $\alpha=1$ :

$$
\begin{aligned}
& \left.\frac{\partial \Phi}{\partial \gamma}\right|_{\alpha=1}=-\frac{A \omega}{\left(1+n_{1, t}\right)^{2} N_{1, t}} \\
& \left.\frac{\partial \Psi}{\partial \gamma}\right|_{\alpha=1}=\frac{A \omega}{\left(1+n_{2, t}\right)^{2} N_{2, t}}
\end{aligned}
$$

as long as $\omega \neq 0$ the effect of an increase in $\gamma$ is negative for Group 1's fertility, and positive for Group 2's fertility.

Keeping $\alpha=1$ and setting $\mu=1$, it is possible to compute each reaction function explicitly, obtaining long expressions. Plugging these expressions into the derivatives of $\Phi$ and $\Psi$ with respect to $A_{t+1}$ evaluated at $\alpha=1$ and $\mu=1$ the following equations hold after simplification:

$$
\begin{aligned}
& \left.\frac{\partial \Phi}{\partial A_{t+1}}\right|_{\alpha=1, \mu=1}=\frac{\lambda}{A_{t+1} \beta \tau} ; \\
& \left.\frac{\partial \Psi}{\partial A_{t+1}}\right|_{\alpha=1, \mu=1}=\frac{\lambda}{A_{t+1} \beta \tau} .
\end{aligned}
$$

Again, provided the reactions functions have positive slopes, we can see that the effect of $A_{t+1}$ on fertility rates is positive in the neighborhood of $\mu=1$ and $\alpha=1$. 